\title{
Regulation of Muscle Protein Synthesis in Neonatal Pigs During Prolonged Endotoxemia
}

\author{
RENÁN A. ORELLANA, SCOT R. KIMBALL, HANH V. NGUYEN, JILL A. BUSH, \\ AGUS SURYAWAN, M. CAROLE THIVIERGE, LEONARD S. JEFFERSON, AND \\ TERESA A. DAVIS.
}

United States Department of Agriculture/Agricultural Research Service Children's Nutrition Research Center [R.A.O., H.V.N., J.A.B., A.S., C.T., T.A.D.] and Pediatric Critical Care Section [R.A.O.], Baylor College of Medicine, Houston, TX, 77030 U.S.A.; and the Department of Cellular and Molecular Physiology, Pennsylvania State University College of Medicine, Hershey, PA, 17033 U.S.A. [S.R.K., L.S.J.].

\section{ABSTRACT}

In adults, protein synthesis in skeletal muscle is reduced by as much as $50 \%$ after a septic challenge, and is associated with repression of translation initiation. Neonates are highly anabolic and their muscle protein synthesis rates are elevated and uniquely sensitive to amino acid and insulin stimulation. In the present study, neonatal piglets were infused with Endotoxin (lipopolysaccharide, LPS) for $20 \mathrm{~h}$ at $0(n=6)$ and $13 \mu \mathrm{g} / \mathrm{kg} \bullet \mathrm{h}(n=8)$. During the last $2 \mathrm{~h}$, dextrose and an amino acid mixture were infused to attain fed plasma concentrations of amino acids, glucose, and insulin. Fractional protein synthesis rates and translational control mechanisms were examined. LPS reduced protein synthesis in glycolytic muscles by only $13 \%$ and had no significant effect in oxidative muscles. This depression was associated with reductions in the phosphorylation of 4E-BP1 $(-31 \%)$ and S6 K1 $(-78 \%)$, and a decrease in eIF4G binding to eIF4E $(-62 \%)$, an event required for formation of the active mRNA binding complex. By comparison, LPS increased protein synthesis in the liver $(+29 \%)$, spleen $(+32 \%)$, and kidney $(+27 \%)$, and in the liver, this increase was associated with augmented eIF4G to eIF4E binding ( $+88 \%)$. In muscle and liver, LPS did not alter eIF2B activity, an event that regulates initiator met-tRNA $\mathrm{i}_{\mathrm{i}}$ binding to the $40 \mathrm{~S}$ ribosomal complex. These findings suggest that during sustained endotoxemia, the high rate of neonatal muscle protein synthesis is largely maintained in the presence of substrate supply, despite profound changes in translation initiation factors that modulate the mRNA binding step in translation initiation. (Pediatr Res 55: 442-449, 2004)

\section{Abbreviations}

LPS, Lipopolysaccharide, endotoxin

$\boldsymbol{\mu g}$, microgram

Kg, kilogram

4E-BP1, eukaryotic initiation factor eIF4E binding protein 1

eIF4G, eukaryotic initiation factor eIF4G

eIF4E, eukaryotic initiation factor eIF4E

S6 K1, ribosomal protein S6 kinase 1

mRNA, mRNA

met-tRNA , initiator methionyl-tRNA
Sepsis is a major cause of mortality and morbidity in the pediatric population $(1,2)$. Several aspects of the inflammatory response seen in adult sepsis, such as elevation of tumor necrosis factor alpha (TNF- $\alpha)$ and alterations in different hormones, such as cortisol, insulin, and IGF I (3-10), may be conditioned by development (11-13). In addition, the metabolic effects of this hormonal response can differ in immature and mature organisms $(11,14)$.

Received March 19, 2003; accepted October 15, 2003.

Correspondence: Teresa A. Davis, Ph.D., USDA/ARS Children's Nutrition Research Center, Baylor College of Medicine, 1100 Bates Street, Houston, TX 77030, U.S.A.; e-mail: tdavis@bcm.tmc.edu

Supported, in part, by grants from the National Institutes of Health (NIH) AR4447 (T.A.D.), United States Department of Agriculture/Agricultural Research Service 625051000-031 (T.A.D.), NIH DK15658 (L.S.J.), NIH DK13499 (L.S.J.) and the NIH training grant T32 HD07445.

DOI: 10.1203/01.PDR.0000110526.02282.F3
In septic adults, reduced protein synthesis and increased proteolysis both contribute to the catabolism of muscle protein (15). The reduction in protein synthesis can be profound, immediate, and sustained in adult models of sepsis $(16,6)$. In contrast, we previously demonstrated in the neonatal pig that when substrate supply is maintained, the high rate of neonatal muscle protein synthesis is largely sustained during acute endotoxemia, and that this is likely due to a high anabolic drive (14). Healthy neonates have relatively high muscle protein synthetic rates that are markedly stimulated by the postprandial rise in both amino acids and insulin (17-22). This response decreases rapidly with development $(17,21,23)$. This maturational change occurs in part as a consequence of developmental changes in the insulin signaling pathway that modulates translation initiation in muscle, with decreased activation of specific 
eukaryotic initiation factors (eIF) involved in 43S ribosomal complex assembly as the neonate develops $(24,25)$.

The insulin-dependent stimulation of protein synthesis occurs, at least in part, by acceleration in the rate of translation of mRNA via alterations in peptide-chain initiation (Fig. 1A). One of the two best-characterized regulatory steps in translation initiation is the binding of the initiator methionyl-tRNA (met-tRNA ${ }_{\mathrm{i}}$ ) to the $40 \mathrm{~S}$ ribosomal subunit to form the $43 \mathrm{~S}$ preinitiation complex (Fig. $1 B$ ). This step is modulated by eIF2 (26), whose activity is regulated by the guanine nucleotide exchange factor, eIF2B $(25,26)$. The second well-characterized regulatory process in peptidechain initiation involves the binding of mRNA to the $43 \mathrm{~S}$ preinitiation complex via mediation of the assembly of the eIF4F complex of proteins (Fig. 1B) (27). Phosphorylation and availability of eIF4E increase its association with eIF4G and eIF4A and its ability to bind to the $\mathrm{m}^{7} \mathrm{GTP}$ cap at the $5^{1}$ end of mRNA. The availability of phosphorylated eIF4E is dependent upon decreased affinity of eIF4E for 4E-BP1 via phosphorylation of $4 \mathrm{E}-\mathrm{BP} 1$, a repressor protein that competes with eIF4G for binding to eIF4E $(27,28)$. The release of eIF4E from the 4E-BP1・eIF4E complex enhances the binding of eIF4E to eIF4G and stimulates mRNA to bind to the $43 \mathrm{~S}$ preinitiation complex. Insulin and amino acids stimulate translation initiation by induction of 4E-BP1 phosphorylation and 70-kD ribosomal protein S6 kinase (S6 K1) phosphorylation through a signal transduction pathway in-

A.

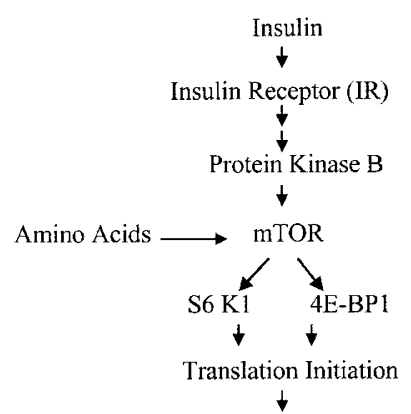

B.

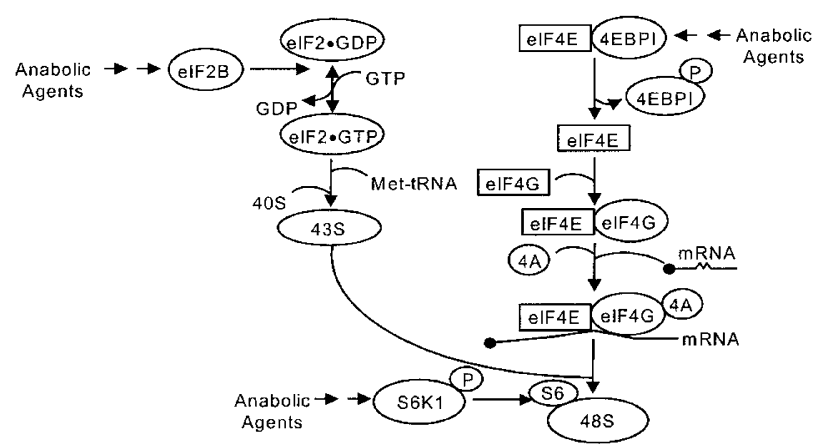

Figure 1. Potential signaling pathway that leads to protein synthesis. Fig. $1 \mathrm{~A}$ depicts the insulin dependent signaling cascade. Fig. $1 B$ shows the sequence of events that promote mRNA translation initiation by assembly of the $48 \mathrm{~S}$ ribosomal subunit. See details in text. volving the mammalian target of rapamicin (mTOR) (Fig. 1A) $(27,28,29)$. mTOR is downstream of protein kinase B (PKB) in the insulin signal transduction pathway $(24,27)$.

In adult rats, LPS has been found to profoundly depress translation initiation in muscle by decreasing eIF2B activity, 4E-BP1 phosphorylation, and eIF4G.eIF4E complex assembly, and increasing the association of the repressor, 4E-BP1, with eIF4E $(6,26)$. When challenged acutely with endotoxin, neonatal animals also reduce the activation of translation initiation factors that modulate the mRNA binding step in muscle (30).

We hypothesized that the high anabolic drive of the newborn organism may protect muscle against the catabolic state induced by sepsis, even during a prolonged septic state. To address this hypothesis, we examined skeletal muscle protein synthesis in neonatal pigs infused with Escherichia coli (E. coli) endotoxin (lipopolysaccharide, LPS), which in adult animals has been shown to replicate many of the metabolic effects of sepsis $(9,31)$. For purposes of comparison, protein synthesis also was measured in tissues that are less responsive to anabolic stimuli (i.e. feeding, amino acids, IGF-1, and insulin) and exhibit little or no developmental change in protein synthesis $(17,19,20,32)$. To identify the mechanisms involved in the regulation of protein synthesis during prolonged endotoxemia in neonates, we examined the activation of translation initiation factors that mediate the mRNA and met-tRNA $A_{i}$ binding steps. The results show that prolonged endotoxemia does not reduce muscle protein synthesis beyond levels reported previously in pigs subjected to a short-term endotoxin challenge (14), despite profound reductions in the activation of mTOR-dependent translation initiation factors involved in the binding of mRNA to the 40S ribosomal subunit, but not in the regulation of met-tRNA ${ }_{\mathrm{i}}$ binding to the $40 \mathrm{~S}$ ribosomal complex.

\section{MATERIALS AND METHODS}

Animals. Two crossbred pregnant sows were housed in lactation crates in individual environmentally controlled rooms for 1 to 2 wk before farrowing. They were fed a commercial diet (5084, PMI Feeds, Richmond, IN, U.S.A.) and provided with water ad libitum. After farrowing, piglets were allowed to remain with the sow and were not given supplemental creep feed. Three days before the study, piglets were anesthetized with isofluorane anesthesia (Aerrane; Anaquest, Madison, WI, U.S.A.) and catheters were inserted into a jugular vein and carotid artery, using sterile techniques as previously described (33). Piglets were returned to the sow and allowed to suckle freely until studied. The study was approved by the Animal Care and Use Committee of Baylor College of Medicine and was conducted in accordance with the National Research Council's Guide for the Care and Use of Laboratory Animals.

Experimental Design. Fourteen piglets (5-6 d of age; $2.1 \pm$ $0.14 \mathrm{~kg}$ ) from two litters were assigned randomly to control ( $n$ $=6)$ and LPS $(n=8)$ treatment groups. When beginning the study, the animals were removed from the sow and placed in individual cages in a heated room $\left(84^{\circ} \mathrm{F}\right)$, with free access to 
water but no feed. The arterial and venous catheters were accessed for infusions and blood sampling, respectively. Between sampling times, the catheter was filled with normal saline solution containing $30 \mathrm{IU} / \mathrm{mL}$ of sodium heparin.

The treatment group received a continuous infusion $[10$ $\mu \mathrm{g} /(\mathrm{kg} \cdot \mathrm{h})]$ of Escherichia coli endotoxin (LPS, lyophilized $E$. coli serotype 0111-B4, Sigma Chemical Co. Chemical Co, St. Louis, MO, U.S.A.) that was increased to $13.3 \mu \mathrm{g} /(\mathrm{kg} \cdot \mathrm{h})$ at $14 \mathrm{~h}$, and was continued for $20 \mathrm{~h}$ while the control group received an equal volume of sterile normal saline solution ( $0.9 \%$ sodium chloride) at the same rate as the LPS infusion. Based on pilot work, prior studies in neonatal piglets (14), and prior reports on LPS porcine models $(13,31)$, this dose of LPS produces a septic-like response during a short 8 -h infusion, and allows most animals to survive at least $20 \mathrm{~h}$. We opted to increase the LPS infusion rate after $14 \mathrm{~h}$ to overcome the possibility of endotoxin resistance. Measurements of rectal temperature and circulating concentrations of TNF- $\alpha$, cortisol, insulin, glucose, branched-chain amino acids (BCAA), serum bicarbonate, and lactate were obtained at baseline and 1, 2, 4, $8,12,16,18,19$, and $20 \mathrm{~h}$ after the infusion began. After LPS/saline infusion and fasting for $18 \mathrm{~h}$, the pigs were transferred to a sling restraint system, and infused for $2 \mathrm{~h}$ with dextrose at a rate of $13 \mathrm{mg} /(\mathrm{kg} \cdot \mathrm{min})$ and a balanced amino acid mixture (20) at a rate of $1.8 \mathrm{mmol}$ total amino acids $/(\mathrm{kg} \cdot \mathrm{h})$ to simulate a normal fed state, while the LPS or saline infusion was maintained for 2 additional hours.

Substrate, TNF- $\alpha$, cortisol, and insulin assays. Plasma glucose and lactate concentrations were determined by a glucose oxidase reaction (YSI 2300 STAT Plus, Yellow Springs Instruments, Yellow Springs, OH, U.S.A.). Plasma concentrations of total BCAA were measured by analysis of leucine, isoleucine, and valine deamination by leucine dehydrogenase with stoichiometric reduction of NAD measured by spectrophotometry (34). Immunoreactive TNF- $\alpha$ concentrations were measured using swine solid-phase sandwich ELISAs with swine antibodies and standards (Biosource International, Camarillo, CA, U.S.A.). Plasma cortisol concentration was determined using a human RIA (RIA) kit with the appropriate standardization (Diagnostic Systems Laboratory, Webster, TX). Plasma insulin concentrations were measured using a porcine insulin RIA kit (Linco, St. Charles, MO, U.S.A.). Serum bicarbonate, mixed venous saturation, and $\mathrm{Po}_{2}\left(\mathrm{PaO}_{2}\right)$ was determined by venous blood gas determination (Rapidlab Model 248, Chiron Diagnostics, East Walple, MA, U.S.A.). Base excess was calculated using the Siggaard-Andersen Equation for calculation of in vitro base excess (35).

Protein synthesis in vivo. Tissue protein synthesis was measured in vivo using a modification of the flooding dose technique $(36,37)$. Nineteen hours and $30 \mathrm{~min}$ after the LPS infusion began, pigs were injected via the jugular vein catheter with $1.5 \mathrm{mmol} / \mathrm{kg}$ body weight ( $1 \mathrm{mCi} / \mathrm{kg}$ body weight) of a flooding dose of L- $\left[4-{ }^{3} \mathrm{H}\right]$ phenylalanine (Amersham, Arlington Heights, IL, U.S.A.). Blood samples were taken at 5, 15, and $30 \mathrm{~min}$ after the injection for measurement of the specific radioactivity of the extracellular free pool of phenylalanine. Immediately after the 30-min blood sample was obtained and $20 \mathrm{~h}$ after the LPS infusion was initiated, pigs were euthanized with an i.v. dose of pentobarbital sodium $(50 \mathrm{mg} / \mathrm{kg}$ body weight). Longissimus dorsi, gastrocnemius, masseter, diaphragm, and cardiac muscles, liver, stomach, jejunum, lung, pancreas, kidney, skin and brain were rapidly removed, frozen in liquid nitrogen, and stored at $-70^{\circ} \mathrm{C}$ until analysis (20).

Frozen tissues were processed as previously described (14, 36,37 ). Phenylalanine in the protein hydrolysate, homogenate supernatant, and blood supernatant was separated from other amino acids by anion exchange chromatography (AS8 column, Dionex, Sunnyvale, CA, U.S.A.). Fractions were collected and the radioactivity associated with the phenylalanine peak was measured in a liquid scintillation counter (TM Analytic, Elk Grove Village, IL, U.S.A.).

Calculations. The fractional rate of protein synthesis (Ks), the percent of protein mass synthesized in a day, was calculated as :

$$
\mathrm{Ks}(\% / \text { day })=\left[\left(\mathrm{S}_{\mathrm{B}} / \mathrm{S}_{\mathrm{A}}\right) \times(1440 / \mathrm{t})\right] \times 100 ;
$$

where $S_{B}$ is the specific radioactivity of the protein-bound phenylalanine, $S_{A}$ is the mean specific radioactivity of the tissue-free phenylalanine during the labeling period determined from the amount at the time of tissue collection, corrected by linear regression of the change in blood specific radioactivity against time, and $t$ is the time of labeling in minutes. Previously, we have demonstrated that the specific radioactivity of the tissue free phenylalanine following a flooding dose of phenylalanine is in equilibrium with the aminoacyl-tRNA specific radioactivity; hence, the tissue free phenylalanine reflects the specific radioactivity of the tissue precursor pool (37).

Measurement of eIF2B activity. Fresh tissues were processed to examine the activation of signaling to eIF2B. The eIF2B activity in muscle and liver supernatants was measured as the exchange of $\left[{ }^{3} \mathrm{H}\right] \mathrm{GDP}$ bound to eIF2 for unlabeled GDP or GTP, as previously described $(25,30,38)$.

Protein immunoblot analysis. Proteins in polyacrylamide gels (PAGE) were electrophoretically transferred to a BioTrace PVDF (polyvinylidene difluoride) membrane (Pall Life Sciences, Pensacola, FL, U.S.A.) as previously described $(25,30$, 38 ). The membranes were then incubated with primary antibody (Amersham Life Sciences, Arlington Heights, IL) for $1 \mathrm{~h}$ at room temperature. Blots were developed using an enhanced chemiluminescence (ECL) Western blotting kit (Amersham Life Sciences, Arlington Heights, IL, U.S.A.), visualized using a GeneGnome bioimaging system, and analyzed using Genetools software (Syngene). Results are expressed as arbitrary units, which represent the band intensity of the integrated pixels being analyzed.

Quantitation of 4E-BP1•eIF4E and eIF4G•eIF4E complexes. Frozen tissue extracts were processed to examine the activation of translation initiation factors that mediate the mRNA and met-tRNA $A_{i}$ binding steps. The association of eIF4E with $4 \mathrm{E}-\mathrm{BP} 1$ or eIF4G was quantitated as described previously $(25,30,38)$.

Determination of $4 E-B P 1$ phosphorylation. Muscle and liver homogenates were heated at $100^{\circ} \mathrm{C}$ for $10 \mathrm{~min}$, cooled to room temperature, and then centrifuged at $10,000 \mathrm{~g}$ for $10 \mathrm{~min}$ at $4^{\circ} \mathrm{C}$. The supernatants were diluted with SDS-sample buffer 
and then subjected to protein immunoblot analysis using an Amersham enhanced chemiluminescence (ECL) Western blotting kit. Previous studies have shown that phosphorylation of 4E-BP1 causes a decrease in the electrophoretic mobility of the protein on SDS-PAGE (38). Thus, 4E-BP1 present in tissue extracts was separated into multiple electrophoretic forms during SDS-PAGE, with the more slowly migrating forms representing more highly phosphorylated 4E-BP1.

Determination of eIF4E phosphorylation. The phosphorylated and unphosphorylated forms of eIF4E in tissue extracts were separated by isoelectric focusing on a slab gel and were quantitated by protein immunoblot analysis with a MAb against eIF4E, as previously described $(25,30,38)$.

Determination of S6 K1 phosphorylation. Muscle and liver homogenates were combined with an equal volume of SDSsample buffer, and the diluted samples were subjected to electrophoresis on $7.5 \%$ polyacrylamide gel. The samples were then analyzed by protein immunoblot analysis by use of rabbit anti-rat S6 K1 polyclonal antibodies (Santa Cruz Biotechnology, Santa Cruz, CA, U.S.A.). Results were normalized by the total amount of S6 K1 on the blot.

Determination of PKB phosphorylation. Muscle and liver samples were homogenized in seven volumes of buffer, and then centrifuged at $10,000 \mathrm{~g}$ for $10 \mathrm{~min}$ at $4^{\circ} \mathrm{C}$. One membrane was incubated with an anti-PKB antibody (New England BioLabs, Beverly, MA, U.S.A.). The second membrane was incubated with a rabbit polyclonal antibody that recognizes the phosphorylation of PKB on Ser (473) (New England BioLabs, Beverly, MA, U.S.A.) $(30,38)$. Results were normalized by the total amount of PKB on the blot.

Statistical analysis. Treatment was the grouping factor for septic and metabolic markers, rate of tissue protein synthesis, and eIF measurements. Difference between groups was determined by a $t$ test. Results are presented as means \pm SE. Probability values of $<0.05$ were considered statistically significant and are presented in figures but not in the text.

\section{RESULTS}

Indicators of sepsis. Body temperature of the animals infused with LPS remained above control values at the end of the experiment (Table 1). A peak in circulating TNF- $\alpha$ concentration was obtained $1 \mathrm{~h}$ after initiation of the LPS infusion (Table 1). TNF- $\alpha$ levels remained higher for $4 \mathrm{~h}$, and then declined to values close to the baseline control animals (data not shown), a pattern similar to that described in a previous study on endotoxemic animals (14).

Plasma cortisol levels were higher in the LPS group after $20 \mathrm{~h}$ of LPS infusion (Table 1). There were no differences between LPS and controls in the average insulin concentration during fasting $(0-18 \mathrm{~h})$, and insulin levels increased in response to the glucose and amino acid infusion in both groups. Average plasma insulin levels were $40 \%$ higher in LPS animals than in controls during the experimental fed state $(18-20 \mathrm{~h})$, but statistical significance was not achieved due to biologic variability in the response (Table 1). Mixed venous saturation tended to be reduced during LPS infusion. The $\mathrm{PO}_{2}\left(\mathrm{PaO}_{2}\right)$ was significantly lower in LPS-treated animals (Table 1). Lactate in
Table 1. Septic and metabolic markers after 20 h of LPS infusion in neonatal pigs

\begin{tabular}{lcc}
\hline \multicolumn{1}{c}{ Markers } & Control & LPS \\
\hline Temperature $\left({ }^{\circ} \mathrm{F}\right)$ & $100.9 \pm 1$ & $103.2 \pm 0.3^{*}$ \\
$\mathrm{TNF}-\alpha(\mathrm{pg} / \mathrm{mL})$ & $7.22 \pm 2.4$ & $909.7 \pm 30.1^{*}$ \\
Cortisol $(\mathrm{mg} / \mathrm{mL})$ & $2.04 \pm 1.70$ & $13.1 \pm 4.2^{*}$ \\
Lactate $(\mathrm{mg} / \mathrm{dL})$ & $0.87 \pm 0.1$ & $1.53 \pm 0.2^{*}$ \\
$\mathrm{PaO}_{2}(\mathrm{~mm} \mathrm{Hg})$ & $38.3 \pm 2.7$ & $31.3 \pm 1.2^{*}$ \\
$\mathrm{Mixed}$ venous saturation $(\%)$ & $70 \pm 4.6$ & $52 \pm 2.4$ \\
Bicarbonate $(\mathrm{nmol} / \mathrm{mL})$ & $23.86 \pm 1.2$ & $22.67 \pm 1.1$ \\
Base excess & $-0.20 \pm 0.83$ & $-1.28 \pm 1.1$ \\
Insulin $(\mu \mathrm{U} / \mathrm{mL})$ & & \\
$\quad$ Fasting state $(0$ to $18 \mathrm{~h})$ & $1.60 \pm 0.3$ & $1.76 \pm 0.4$ \\
Fed state $(18$ to $20 \mathrm{~h})$ & $22.5 \pm 2.1$ & $31.2 \pm 6.1$ \\
Glucose $(\mathrm{mg} / \mathrm{dL})$ & & \\
$\quad$ Fasting state $(0$ to $18 \mathrm{~h})$ & $78 \pm 6$ & $53 \pm 3^{*}$ \\
$\quad$ Fed state $(18$ to $20 \mathrm{~h})$ & $202 \pm 20$ & $148 \pm 14$ \\
BCAA (mmol/mL) & & \\
$\quad$ Fasting state $(0$ to $18 \mathrm{~h})$ & $586 \pm 75$ & $376 \pm 58$ \\
$\quad$ Fed state $(18$ to $20 \mathrm{~h})$ & $820 \pm 50$ & $473 \pm 60^{*}$ \\
\hline
\end{tabular}

Results are presented as means \pm SE. For TNF- $\alpha$, the reported results are the peak levels at $60 \mathrm{~min}$ after LPS infusion. For insulin, glucose, and BCAA, the reported results represent the average at the end of two time periods (fasting period: $0-18 \mathrm{~h}$; experimental fed state: $18-20 \mathrm{~h}$ ).

* Significantly different from control values, $p<0.05$.

plasma was significantly elevated after $20 \mathrm{~h}$ of LPS infusion (Table 1). Plasma bicarbonate level and base excess, measured as a reflection of the acid-base status, was similar in both groups (Table 1).

Whole blood glucose concentrations in the LPS-infused animals were significantly lower during the fasting period $(0-18 \mathrm{~h})$, despite similar insulin levels (Table 1). After initiation of the dextrose infusion, blood glucose concentrations increased in both groups, but tended to be lower in the LPSinfused animals when compared with the controls. Similarly, plasma BCAA concentrations in the LPS-infused animals tended to be lower during the fasting period $(0-18 \mathrm{~h})$ despite similar insulin levels (Table 1). After initiation of the amino acid infusion, serum BCAA concentrations increased in both groups, but were significantly lower in the LPS-infused animals when compared with the controls (Table 1).

Protein synthesis. Fractional rates of protein synthesis in both longissimus dorsi and gastrocnemius muscles, skeletal muscles of glycolytic metabolism, were $13 \%$ lower in the LPS versus the control group (Fig. 2). There was no significant effect of LPS infusion on protein synthesis in muscles with oxidative metabolic properties, i.e. masseter and cardiac muscle (Fig. 2). Protein synthesis in the diaphragm, a muscle of mixed composition, was $29 \%$ higher in the LPS group than in controls (Fig. 2). LPS infusion resulted in higher fractional rates of protein synthesis in liver $(+29 \%)$, spleen $(+32 \%)$, and kidney $(+27 \%)$ (Fig. 3). Protein synthesis rates in jejunum, lung, stomach, pancreas, skin, and brain were unaffected by LPS infusion (Fig. 3).

Translation initiation factors (eIF). In longissimus dorsi, LPS infusion resulted in reductions in phosphorylation of 4E-BP1 $(-31 \%)$ and S6 K1 $(-78 \%)$, and a decrease in the association of eIF4G with eIF4E (-62\%) (Fig. 4). The latter result would be expected to cause a reduction in mRNA binding to the $40 \mathrm{~S}$ ribosomal subunit, for active mRNA bind- 


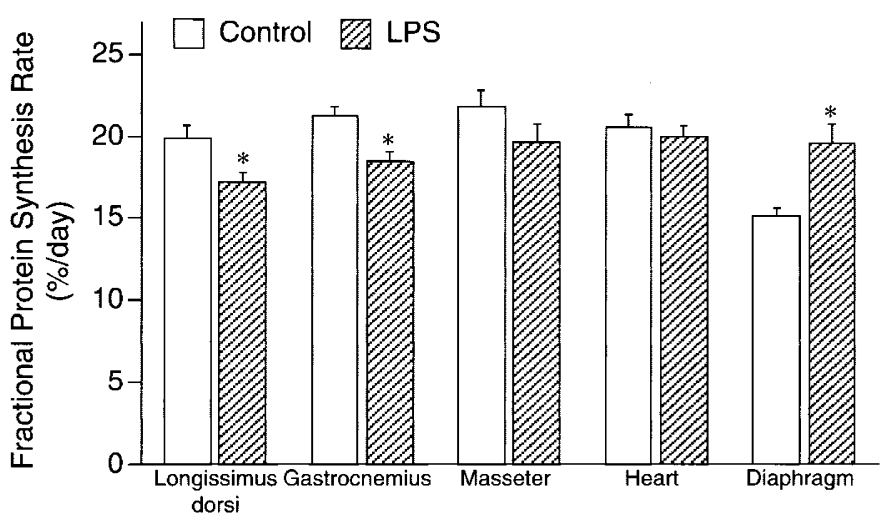

Figure 2. Fractional protein synthesis rates in longissimus dorsi (LD), gastrocnemius, masseter, heart, and diaphragm muscles in LPS and control pigs after a 20-h LPS infusion. Values are means \pm SE; LPS was infused at 0 (controls, $n=$ 6 ) and $13 \mu \mathrm{g} / \mathrm{kg} \bullet \mathrm{h}$ (LPS, $n=8$ ). LPS infusion modestly reduced protein synthesis in LD and gastrocnemius muscles $(p<0.05)$ and increased protein synthesis in diaphragm $(p<0.05)$. *Significantly different from control value $(p<0.05)$.

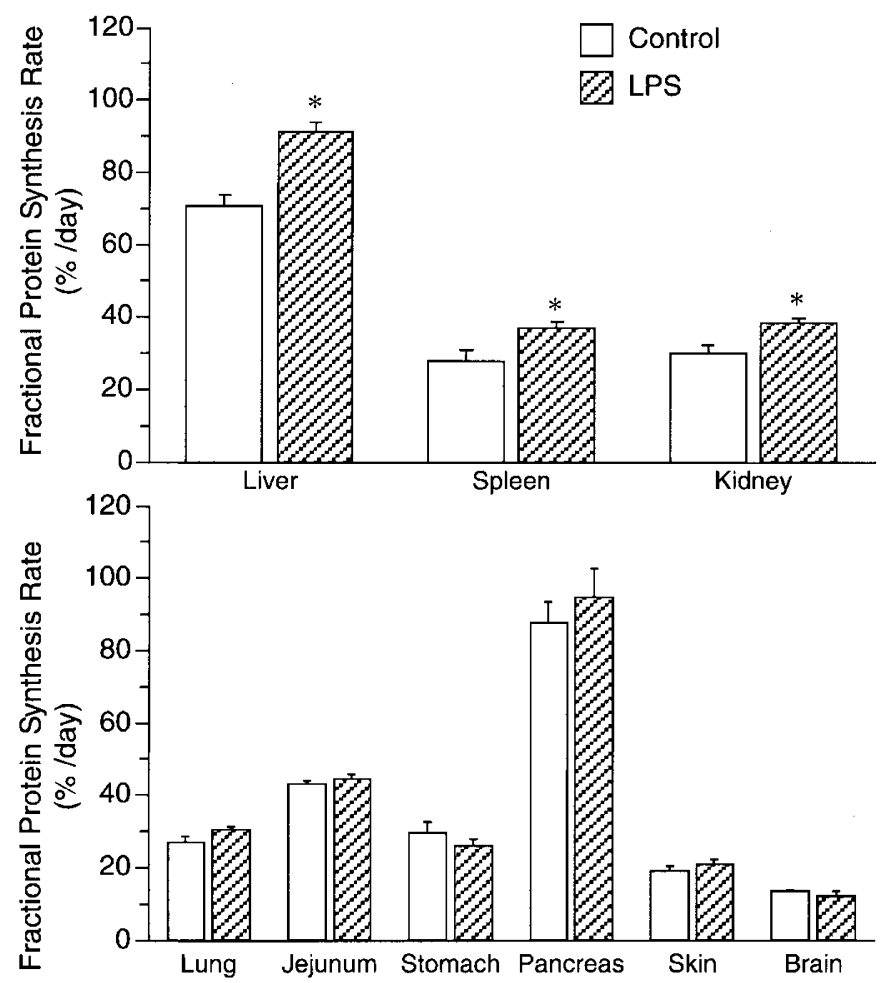

Figure 3. Fractional rates of protein synthesis in liver, jejunum, spleen, kidney, lung, and skin in LPS and control pigs after a 20-h LPS infusion. Values are means $\pm \mathrm{SE}$; LPS was infused at 0 (controls, $n=6$ ) and $13 \mu \mathrm{g} / \mathrm{kg} \bullet \mathrm{h}$ (LPS, $n=8$ ). Protein synthesis in liver, spleen, and kidney was increased in the LPS group ( $p<$ $0.5)$. *Significantly different from control value $(p<0.05)$.

ing complex assembly. By comparison, LPS augmented eIF4G binding to eIF4E ( $+88 \%)$, but not S6 K1 or 4E-BP1 phosphorylation in the liver (Fig. 4). In muscle and liver, LPS did not alter eIF4E phosphorylation, which regulates mRNA binding to the $40 \mathrm{~S}$ ribosomal subunit, or eIF2B activity, which regulates met-tRNA $i$ binding to the $40 \mathrm{~S}$ ribosomal complex (Fig. 4). Similarly, PKB phosphorylation was not affected by LPS in liver or muscle (Fig. 4).
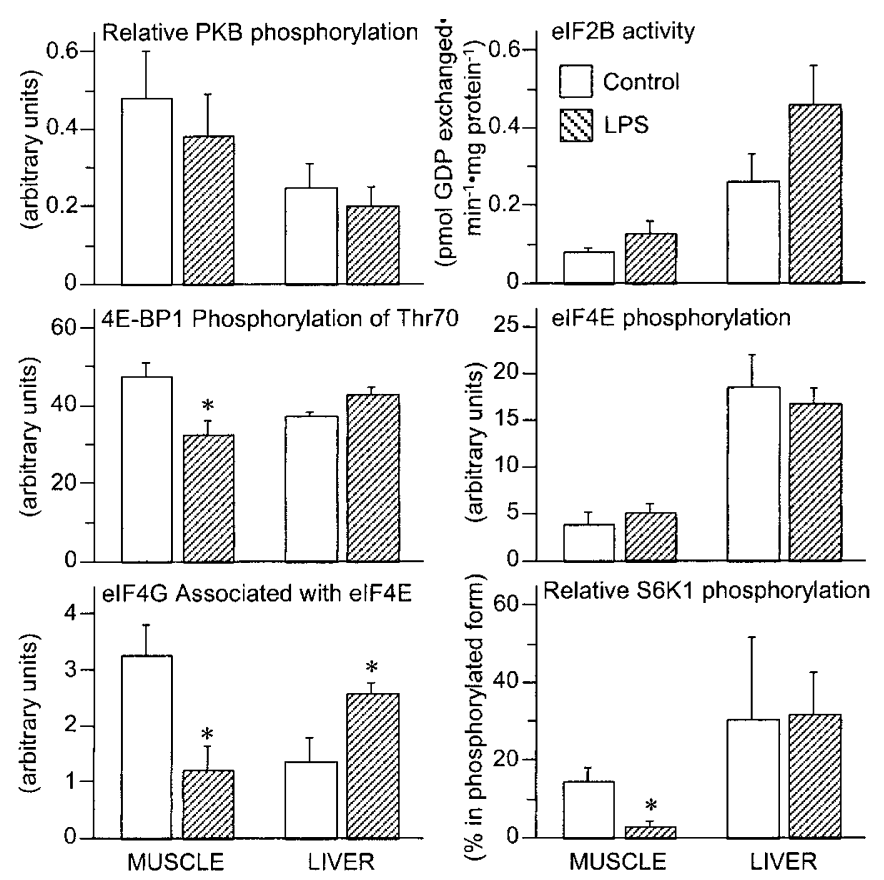

Figure 4. Activation of eukaryotic initiation factors (eIF) during the translational process in muscle and liver of LPS-infused and control pigs after a $20-\mathrm{h}$ LPS infusion. Values are means \pm SE; LPS was infused at 0 (controls, $n=6$ ) and $13 \mu \mathrm{g} / \mathrm{kg} \cdot \mathrm{h}$ (LPS, $n=8$ ). In muscle, LPS depressed the phosphorylation of 4E-BP1 and S6 K1, and decreased binding of eIF4G to eIF4E ( $p>0.05)$. In liver, LPS augmented eIF4G binding to eIF4E and increased 4E-BP1 phosphorylation $(p>0.05)$. *Significantly different from control value $(p<$ $0.05)$.

\section{DISCUSSION}

Previous studies in adult animals, including pigs, have shown that LPS administration reproduces many of the metabolic derangements of sepsis shortly after LPS is infused (9, 14, 31). These include elevations in temperature, heart rate, $\mathrm{TNF}-\alpha$, cortisol and lactate levels. Evidence suggests that when endotoxin is used in a nonlethal dose, the pathophysiological consequences are intracellular and metabolic in nature rather than hemodynamic (39), and those effects persist over a prolonged period of time despite signs of endotoxin resistance (40). Although the response to endotoxin has been validated in adult swine $(9,31)$, developmental variations and differences between species may influence the metabolic response to endotoxin (11-13). In the current study, an elevation of temperature, TNF- $\alpha$ and cortisol was demonstrated after a prolonged endotoxin infusion, similar to the pattern observed in previous studies on endotoxemic models in mature animals $(9,41)$. However, the neonatal animal may have an attenuated response to endotoxin infusion, when compared with the adult $(12,13)$. The dose used in our experiment was comparatively high when contrasted with other adult models of endotoxemic swine, without evidence of major metabolic acidosis or clinically significant lactacidemia $(9,31,40,41)$. Low $\mathrm{PaO}_{2}$ values in the LPS group may suggest increased oxygen uptake by peripheral tissues during endotoxemia, although the difference between values does not offer clinical significance and the mixed venous saturation was not different between both groups. 
Metabolic events during prolonged endotoxemia. In adult humans, evidence suggests that LPS increases pancreatic insulin secretion (4), and that LPS infusion triggers hyperglycemia and an increase in circulating insulin levels similar to that observed in sepsis $(3,10,42)$. This hyperglycemic response in the face of hyperinsulinemia may occur from stress-related hormonal response (e.g. glucagon, cortisol, and epinephrine) and/or insulin resistance $(4,5,11,31)$. In the current study, we found that during the fasting period, the circulating concentrations of insulin did not increase in response to LPS infusion. Although insulin levels in the LPS-infused pigs during the experimentally induced fed state tended to be higher than in fed control animals, as they were in our previous acute LPS infusion study (14), the increase did not achieve statistical significance due to the variability of the response. This suggests that there may be a differential insulin response to LPS in the neonatal animal during fasting and fed states.

Despite the similar circulating insulin concentrations in both groups, blood glucose levels were lower in the LPS-infused animals than in the controls during fasting. Changes in plasma insulin and glucose are difficult to interpret unequivocally as they relate to insulin sensitivity, but lower glycemia in the presence of similar insulin levels in LPS-infused and control animals suggests the absence of insulin resistance for glucose metabolism. Other mechanisms for hypoglycemia during endotoxin infusion in the neonatal animal may include a diminished gluconeogenic capacity, low glycogen stores, and immature glucose metabolism during fasting $(11,43)$. Direct endotoxin stimulation of GLUT1 glucose transporters, which predominate in the neonate and are insulin-independent, also may play a role in neonatal glucose dyshomeostasis during endotoxemia (44).

In a similar manner, serum BCAA were lowered by the LPS infusion, suggesting the absence of insulin resistance for amino acid metabolism. This contrasts with the observed insulin resistance for AA metabolism in an adult rat model of sepsis (45). The high sensitivity to insulin in the neonatal muscle (18, $20,22)$, and an apparent lack of development of insulin resistance during prolonged endotoxemia in the neonate, likely contribute to the lower serum BCAA levels in the LPS group. An increased amino acid uptake by the liver during sepsis (46) also may be involved.

Protein synthesis. Studies in adult animals have shown that sepsis reduces skeletal muscle protein synthesis as early as $4 \mathrm{~h}$ and this reduction is sustained as long as $24 \mathrm{~h}$ after an endotoxin challenge $(6,14,16)$. In this study, the muscle protein synthetic rates in skeletal muscles primarily composed of fast-twitch, glycolytic fibers, i.e. gastrocnemius and longissimus dorsi, which predominate in the neonatal pig, were reduced by $13 \%$ in response to LPS infusion, similar to the reductions that occur in those muscles after a short-term endotoxin infusion (14). LPS did not affect masseter and heart muscles, which have primarily oxidative properties. As was the case in our previous report (14), protein synthesis in the diaphragm, a muscle of mixed composition, was significantly increased, perhaps due to the increased respiratory work observed in our LPS-infused animals.
Because insulin resistance has been implicated in the reduction in protein synthesis in different adult models of sepsis (26, 45 ), we speculate that the fact that muscle protein synthesis was only modestly reduced in this neonatal model of endotoxemia may be ascribed to the unique sensitivity and responsiveness of neonatal muscle protein synthesis to insulin and amino acids. Because of the endogenous production of insulin induced by glucose and amino acid infusion, the enhanced sensitivity of neonatal muscle protein synthesis to these anabolic agents $(17,18,20,22)$, and the lack of apparent insulin resistance in this model, it appears that the elevation in insulin and/or amino acids to fed levels $(18,22,27)$ may have circumvented some of the catabolic effects induced by the septic-like state (15) and blunted the reduction in muscle protein synthesis by endotoxin. The response of muscle protein synthesis to insulin in adult septic rats is characterized by both a decreased sensitivity and a decreased maximal responsiveness compared with control rats (26). More detailed study is required to determine whether insulin modulates muscle protein synthesis in neonates during septic states.

During sepsis, whole-body protein synthesis is enhanced as a result of increased visceral tissue protein synthesis (47), despite the reduction in muscle protein synthesis. In the current study, we found an increase in hepatic protein synthesis in neonatal pigs infused with LPS that may reflect the stressinduced synthesis of acute-phase reactants $(8,46,47)$. Other organs that presented an increased protein synthesis response were the spleen and kidney, as in our previous report on short-term LPS infusion (14). In healthy neonatal animals, visceral protein synthesis is not dependent on insulin, and different mechanisms regulate the growth of peripheral and visceral tissues in the neonate $(19,20)$. The degree and acuity of the septic insult likely affect the severity of the immune activation and the changes in protein synthesis of certain immunogenic organs during sepsis, such as the lung, liver, spleen, and small intestine (47). Similar to the findings of our short-term LPS infusion study, protein synthesis was not affected in the stomach, pancreas, brain, or skin (14).

Translation initiation during neonatal endotoxemia. Translation initiation in neonatal muscle is enhanced by insulin and amino acids in normal conditions $(24,25,27)$. Studies in adult animals have shown that translation initiation in glycolytic muscles is profoundly reduced during sepsis by suppressing both mRNA and met-tRNA $\mathrm{i}_{\mathrm{i}}$ binding to the $40 \mathrm{~S}$ ribosomal complex, and those changes included a decreased eIF4G・eIF4E complex formation (26) and eIF2B activity $(6,16,26)$. In our study in neonatal animals, PKB phosphorylation was not affected by LPS in liver or muscle, suggesting a lack of effect of endotoxin on the early steps of the insulin signal transduction pathway. The depression in translation initiation downstream in the insulin signaling transduction pathway in muscle was manifested as profound reductions in phosphorylation of 4EBP1 and S6 K1, and a decrease in binding of eIF4G to eIF4E, thereby affecting active mRNA binding complex formation with a simultaneous decrease in protein synthesis. In contrast, LPS increased protein synthesis in the liver, and this increase was associated with augmented eIF4G to eIF4E binding. In muscle and liver, LPS did not alter eIF4E phosphorylation, 
which is involved in the regulation of mRNA binding to the $40 \mathrm{~S}$ ribosomal subunit, or eIF2B activity, which regulates met-tRNA $_{i}$ binding to the $40 \mathrm{~S}$ ribosomal complex, in contrast to findings in adult septic rats (26). Because the depression in the transduction pathway associated with mTOR-dependent translation initiation factors 4E-BP1 and S6 K1 was coupled with only a modest decrease in muscle protein synthesis, we hypothesize that other mechanisms that promote selective regulation in gene expression, such as crosstalk activity between or concurrent activation of simultaneous intracellular pathways (30, 48) influenced by amino acids and/or insulin stimulation, may affect the modulation of protein synthesis in endotoxin-infused neonatal animals. For example, studies have shown that S6 K1induced phosphorylation of ribosomal protein $\mathrm{S} 6$ promotes the translation of mRNAs that encode proteins important for cell growth (i.e. TOP mRNAs, which represent only a fraction of total mRNA), and has little effect on the translation of most mRNAs (30). In addition, the lack of effect of LPS on the eIF2-dependent regulatory process of translation initiation as a result of the preservation of insulin sensitivity may account for the near preservation of global rates of muscle protein synthesis in the neonate during sepsis (30), in contrast to septic mature animals, where both eIF2 and eIF4 signaling cascades are repressed $(6,16)$.

\section{CONCLUSIONS}

In summary, in the present study, we demonstrate that neonatal animals, unlike adults, are relatively resistant to a sepsis-induced reduction in muscle protein synthesis after a prolonged infusion of LPS. This modest reduction in muscle protein synthesis is associated with more profound changes in mTOR-dependent translation initiation factors that modulate the mRNA binding step in translation initiation, but not in the regulation of met-tRNA binding to the $40 \mathrm{~S}$ ribosomal complex.

The small reduction in protein synthesis in skeletal muscle of LPS-infused neonatal pigs contrasts with the marked reduction in skeletal muscle protein synthesis reported in different models of adult sepsis $(6,16)$, and may be due to the apparent lack of insulin resistance in this neonatal model. In consequence, the results of the current study show that, when substrate supply is maintained, the high rate of neonatal muscle protein synthesis is largely maintained during prolonged endotoxemia despite profound changes in the translation initiation factors that modulate the mRNA binding step in translation initiation, suggesting that other simultaneous signaling mechanisms are involved.

Acknowledgments. The authors thank William Liu and Susan Nguyen for technical assistance, Frankie Biggs and Jerome Stubblefield for assistance with care of animals, Adam Gillum for graphics assistance, and Leslie Loddeke for editorial assistance, and Linda Weiser for secretarial assistance.

\section{REFERENCES}

1. Proulx F, Fayon M, Farrell CA, Lacroix J, Gauthier M 1996 Epidemiology of sepsis and multiple organ dysfunction syndrome in children. Chest 109:1033-1037

2. Angus DC, Linde-Zwirble WT, Lidicker J, Clermont G, Carcillo J, Pinsky MR 2001 Epidemiology of severe sepsis in the United States: analysis of incidence outcome and associated costs of care. Crit Care Med 29:1303-1310

3. Agwunobi AO, Reid C, Maycock P, Little RA, Carlson GL 2000 Insulin resistance and substrate utilization in human endotoxemia. J Clin Endocrinol Metab 85: 3770-3778
4. Lang CH 2001 Sepsis-induced changes in pancreatic hormone secretion. In: Jefferson LS and Cherrington AD (eds) Handbook of Physiology. Oxford University Press, Oxford, pp 999-1014

5. Lang CH, Dobrescu C, Meszaros K 1990 Insulin-mediated glucose uptake by individual tissues during sepsis. Metabolism 39:1096-1107

6. Lang CH, Frost RA, Jefferson LS, Kimball SR, Vary TC 2000 Endotoxin-induced decrease in muscle protein synthesis is associated with changes in eIF2B, eIF4E, and IGF-I. Am J Physiol Endocrinol Metab 278:E1133-E1143

7. Oberholzer A, Oberholzer C, Moldawer LL 2000 Cytokine signaling- regulation of the immune response in normal and critically ill states. Crit Care Med 28: N3-N12

8. Wesley J 1998 Nutrient metabolism in relation to the systemic stress response. In: Fuhrman BP and Zimmerman JJ (eds) Pediatric Critical Care. Mosby, St Louis, pp 799-819

9. Webel DM, Finck BN, Baker DH, Johnson RW 1997 Time course of increased plasma cytokines, cortisol, and urea nitrogen in pigs following intraperitoneal injection of lipopolysaccharide. J Anim Sci 75:1514-1520

10. Wolfe RR 1997 Substrate utilization/insulin resistance in sepsis/trauma. Bailliere's Clin Endocrinol Metab 11:645-657

11. Yelich MR, Witek-Janusek L 1994 Glucose, lactate, insulin, and somatostatin responses to endotoxin in developing rats. Shock 6:438-444

12. Chorinchath BB, Kong LY, Mao L, McCallum RE 1996 Age-associated differences in TNF- $\alpha$ and nitric oxide production in endotoxic mice. J Immunol 156:1525-1530

13. Li JX, Oliver JR, Lu CY, Grantham KD, Philips JB III 1993 Age related differences in responses to endotoxin in unanesthetized piglets. Circulatory Shock 41:40-47

14. Orellana RA, O'Connor PMJ, Nguyen HV, Bush JA, Suryawan AS, Thivierge MC, Fiorotto ML, Davis TA 2002 Endotoxemia reduces skeletal muscle protein synthesis in neonates. Am J Physiol Endocrinol Metab 283:E909-916

15. Cooney RN, Kimball SR, Vary TC 1997 Regulation of skeletal muscle protein turnover during sepsis: mechanisms and mediators. Shock 7:1-16

16. Vary TC, Kimball SR 1992 Sepsis-induced changes in protein synthesis: differential effects on fast- and slow-twitch muscles. Am J Physiol Cell Physiol 262:C1513-C1519

17. Davis TA, Burrin DG, Fiorotto ML, Nguyen HV 1996 Protein synthesis in skeletal muscle and jejunum is more responsive to feeding in 7- than 26-day-old pigs. Am J Physiol Endocrinol Metab 270:E802-E809

18. Davis TA, Burrin DG, Fiorotto ML, Reeds PJ, Jahoor F 1998 Role of insulin and amino acids in the regulation of protein synthesis in the neonate. J Nutr 128:347S-350S

19. Davis TA, Fiorotto ML, Beckett PR, Burrin DG, Reeds PJ, Wray-Cahen D, Nguyen HV 2001 Differential effects of insulin on peripheral and visceral tissue protein synthesis in neonatal pigs. Am J Physiol Endocrinol Metab 280:E770-E779

20. Davis TA, Fiorotto ML, Burrin DG, Reeds PJ, Nguyen HV, Beckett PR, Vann RC, O'Connor PM 2002 Stimulation of protein synthesis by both insulin and amino acids is unique to skeletal muscle in neonatal pigs. Am J Physiol Endocrinol Metab 282:E880-890

21. Davis TA, Fiorotto ML, Nguyen HV, Reeds PJ 1993 Enhanced response of muscle protein synthesis and plasma insulin to food intake in suckling rats. Am J Physiol 265:R334-R340

22. Preedy VR, Garlick PJ 1993 Response of muscle protein synthesis to parenteral administration of amino acid mixtures in growing rats. JPEN J Parenter Enteral Nutr 17:113-118

23. Tessari P, Zannetti M, Barazzoni R, Vettore M, Michielan F 1996 Mechanism of postprandial protein accretion in human skeletal muscle. Insight from leucine and phenylalanine forearm kinetics. J Clin Invest 98:1361-1372

24. Kimball SR, Farrell PA, Nguyen HV, Jefferson LS, Davis TA 2002 Developmental decline in components of signal transduction pathways regulating protein synthesis in pig muscle. Am J Physiol Endocrinol Metab 282:E585-E592

25. Davis TA, Nguyen HV, Suryawan AS, Bush JA, Jefferson LS, Kimball SR 2000 Developmental changes in the feeding-induced stimulation of translation initiation in muscle of neonatal pigs. Am J Physiol Endocrinol Metab 279:E1226-1234

26. Vary TC, Jefferson LS, Kimball SR 2001 Insulin fails to stimulate protein synthesis in sepsis despite unimpaired signaling to 4E-BP1 and S6K1. Am J Physiol Endocrinol Metab 281:E1045-E1053

27. Kimball SR 2002 Regulation of global and specific mRNA translation by amino acids. J Nutr 132:883-886

28. Proud CG, Denton RM 1998 Molecular mechanisms for the control of translation by insulin. Biochem J 328:329-341

29. Kimball SR, Horetsky RL, Jefferson LS 1998 Signal transduction pathways involved in the regulation of protein synthesis by insulin in L6 myoblasts. Am J Physiol 274:C221-228

30. Kimball SR, Orellana RA, O'Connor PMJ, Suryawan AS, Bush JA, Nguyen HV, Thivierge MC, Jefferson LS, Davis TA 2003 Endotoxin induces differential regulation of mTOR-dependent signaling in skeletal muscle and liver of neonatal pigs. Am J Physiol Endocrinol Metab 285:E637-E644

31. Fink MP, Heard SO 1990 Laboratory models of sepsis and septic shock. J Surg Res 49:186-196

32. Davis TA, Fiorotto ML, Burrin DG, Vann RC, Reeds PJ, Nguyen HV, Beckett PR, Bush JA 2002 Acute IGF-I infusion stimulates protein synthesis in skeletal muscle and other tissues of neonatal pigs. Am J Physiol Endocrinol Metab 283:E638-47

33. Wray-Cahen D, Beckett PR, Nguyen HV, Davis TA 1997 Insulin-stimulated amino acid utilization during glucose and amino acid clamps decreases with development. Am J Physiol Endocrinol Metab 273:E305-E314

34. Beckett PR, Hardin DS, Davis TA, Nguyen HV, Wray-Cahen D, Copeland KC 1996 Spectrophometric assay for measuring branched chain amino acid concentrations: applications for measuring the sensitivity of protein metabolism to insulin. Anal Biochem 240:48-53

35. Siggaard-Andersen O 1966 Titratable acid or base of body fluids. Ann NY Acad Sci 133:41-58

36. Garlick PJ, McNurlan MA, Preedy VR 1980 A rapid and convenient technique for measuring the rate of protein synthesis in tissues by injection of ${ }^{3} \mathrm{H}$-phenylalanine. Biochem J 192:719-723 
37. Davis TA, Fiorotto ML Nguyen HV, Burrin DG 1999 Aminoacyl-tRNA and tissue free amino acid pools are equilibrated after a flooding dose of phenylalanine. Am J Physiol Endocrinol Metab 277:E103-109

38. Bush JA, Kimball SR, O'Connor PMJ, Suryawan AS, Orellana RA, Nguyen HV, Jefferson LS, Davis TA 2003 Translational control of protein synthesis in muscle and liver of growth-hormone-treated pigs. Endocrinology 144:1273-1283

39. Fish RE, Lang CH, Spitzer JA 1986 Regional blood flow during continuous endotoxin infusion. Circ Shock 18:267-275

40. McCowen KC, Ling PR, Ciccarone A, Mao Y, Chow JC, Bistrian BR, Smith RJ 2001 Sustained endotoxemia leads to marked down-regulation of early steps in the insulinsignaling cascade. Crit Care Med 29:839-846

41. Ertel W, Morrison MH, Wang P, Ba ZF, Ayala A, Chaudry IH 1991 The complex pattern of cytokines in sepsis. Associations between prostaglandins, cachectin, and interleukins. Ann Surg 214:141-148

42. Shangraw RE, Jahoor F, Miyoshi H, Neff WA, Stuart CA, Herndon DN, Wolfe R 1989 Differentiation between septic and post burn insulin resistance. Metabolism 38:983-989
43. Goto M, Zeller WP, Lichtemberg RC 1994 Decreased gluconeogenesis and increased glucose disposal without hyperinsulinemia in 10 day-old rats with endotoxic shock. Metabolism 43:1248-1254

44. Battelino T, Goto M, Krzisnik C, Zeller WP 1996 Tissue glucose transport and glucose transporters in suckling rats with endotoxic shock. Shock 6:259-262

45. Jurasinski CU, Gray K, Vary TC 1995 Modulation of skeletal muscle protein synthesis by amino acids and insulin during sepsis. Metabolism 44:1130-1138

46. Hasselgren PO, Pedersen P, Sax HC, Warner BW, Fischer JE 1988 Current concepts of protein turnover and amino acid transport in liver and skeletal muscle during sepsis. Arch Surg 123:992-999

47. Breuillé D, Arnal M, Rambourdin F, Bayle G, Levieux D, Obled C 1998 Sustained modifications of protein metabolism in various tissues in a rat model of long-lasting sepsis. Clin Sci 94:413-423

48. Keeton AB, Amsler MO, Venable DY, Messina JL 2002 Insulin signal transduction pathways and insulin induced gene expression. J Biol Chem 277:48565-48573 